\title{
EXENTERAÇÃO PÉLVICA E TRATAMENTO DO CÂNCER DO RETO
}

DESCRITORES - Exenteração pélvica. Neoplasias retais.

Quando se visa a possibilidade de cura do câncer retal, a cirurgia desempenha papel fundamental, tanto para os portadores de lesões iniciais, submetidos a ressecções clássicas, como para os tumores localmente avançados, candidatos a ressecções ampliadas.

A incidência dos tumores localmente avançados varia de $5 \%$ a $22 \%$ na literatura, podendo infiltrar os ureteres, bexiga, próstata, vesículas seminais, ovários, útero, vagina, alças intestinais e parede pélvica. Quando houver evidência de invasão por contigüidade, não se recomenda a lise de aderências por digitoclasia porque essa manobra pode disseminar células neoplásicas, apesar de muitas vezes serem apenas inflamatórias e não devido à invasão maligna. A diferenciação entre processo inflamatório e tumoral é impossível ao cirurgião, não sendo recomendada a feitura de biopsias para congelação.

Numerosos trabalhos têm sido descritos mostrando as vantagens das ressecções em bloco, no que diz respeito aos índices de recidivas loco-regionais e quanto à sobrevida. Quando necessária, a realização de exenteração pélvica oferece maior sobrevida, apesar de envolver morbidade e mortalidade importantes. Na presença de acometimento ganglionar, há autores que acreditam que o procedimento não traz benefícios reais quanto à sobrevida.

Desde a descrição da exenteração pélvica em 1948 por Brunschwig para câncer avançado do colo do útero, o procedimento tem evoluído. Tradicionalmente, a ressecção multivisceral na pelve envolve a extirpação total de vísceras (bexiga, útero na mulher e reto) com colostomia permanente e derivação urinária. Este procedimento tem sido modificado ao longo dos anos para dar lugar à exenteração pélvica posterior (reto, útero e parede posterior da vagina) e à exenteração pélvica anterior (bexiga e útero). Outra modificação introduzida é a chamada exenteração pélvica supra-elevador, onde os órgãos pélvicos são excisados ao nível do músculo elevador, preservando a porção distal do reto e o diafragma urogenital. Modificações posteriores visaram estabelecer a continuidade intestinal de maneira a se evitar a colostomia na exenteração pélvica total e na exenteração pélvica posterior. De fato, com refinamento técnico tem sido realizado exenteração pélvica total com anastomose colo-anal e construção de uma neobexiga ortotópica. Por outro lado, tem sido proposta a exenteração pélvica estendida, modificação ultra-radical que se associa à ressecção do sacro.

O objetivo da exenteração pélvica é a ressecção do tumor com margens livres (R0). Tumores retais que invadam órgãos vizinhos (T4) devem ser tratados com alguma forma de exenteração pélvica, embora a radioterapia e a quimioterapia em neo-adjuvância possam contribuir para aumento da ressecabilidade e diminuição da recidiva.

No trabalho "A exenteração pélvica no tratamento do câncer do reto estádio T4: experiência de 15 casos operados", publicado neste número dos ARQUIVOS de GASTROENTEROLOGIA, os autores fazem uma revisão atual e criteriosa do assunto, descrevendo as operações realizadas e os resultados obtidos quanto à morbidade e mortalidade, comparando-os com os da literatura. Concluem pela justificativa do método e destacam a necessidade de seleção adequada dos pacientes e os benefícios obtidos. Sem dúvida, trata-se de excelente contribuição, pois, preenche uma lacuna em nosso meio, que era a falta de relato de uma série exclusiva de tratamento de tumores retais $\mathrm{T} 4$.

Pela relevância da questão, proponho a continuidade do estudo e futuras publicações para a divulgação do método.

José Hyppolito da SILVA*

Silva JH. Pelvic exenteration and treatment of cancer of the rectum. Arq Gastroenterol. 2007;44(4):283.

HEADINGS - Pelvic exenteration. Rectal neoplasms.

\section{REFERÊNCIAS}

Chen HS, Sheen-Chen SM. Total pelvic exenteration for primary local advanced colorectal cancer. World J Surg. 2001;25:1546-9.

Costa SRP, Antunes RCP, Paula RP, Pedroso MA, Farah JFM, Lupinacci RA. A exenteração pélvica no tratamento do câncer de reto estádio T4: experiência de 15 casos operados. Arq Gastroenterol. 2007;44:284-8. Gannon CJ, Zager JS, Chang GJ, Feig BW, Wood CG, Skibber JM, RodriguezBigas MA. Pelvic exenteration affords safe and durable treatment for locally advanced rectal carcinoma. Ann Surg Oncol. 2007;14:1870-7.
Ike H, Shimada H, Yamaguchi S, Ichikawa Y, Fujii S, Ohki S. Outcome of total pelvic exenteration for primary rectal cancer. Dis Colon Rectum. 2003;46:474-80.

Lopes A, Poletto AHO. Tratamento cirúrgico do reto: ressecções ampliadas. In: Rossi BM, Nakagawa WT, Ferreira FO, Aguiar Jr S, Lopes A, editores. Câncer de cólon, reto e ânus. São Paulo: Lemar e Tecmedd; 2004. p.353-65.

Pandey D, Zaidi S, Mahajan V, Kannan R. Pelvic exenteration: a perspective from a regional cancer center in India. Indian J Cancer [serial on line] 2004 [cited 2007 Oct 22];41:109-14. Available from : http://www.indianjcancer.com 